\title{
DE LAS ARMAS Y LAS LETRAS HACIA PACHAMÃE
}

\author{
Dani Velásquez Romero ${ }^{1}$
}

\begin{abstract}
Resumen: Este texto pretende dar a conocer un largo proceso de investigación y de acción, con algunos resultados que a su vez se convierten en nuevas preguntas, en desdoblamientos que abren otros caminos y nos conectan a su vez con otras fuentes, con otras investigaciones, con otras redes que le dan cuerpo y espíritu a esa ardua e interminable búsqueda del conocimiento y de la transformación social. En nuestro caso, conocimiento(s) y acciones que nos lleven a la descolonización, a la liberación, que nos ayuden a superar la opresión y la dominación de una única forma de pensamiento, de un proyecto fracasado que nos ha conducido a la catástrofe civilizatoria que estamos viviendo. Proyecto colonizador que no termina y que desde sus inicios, allá en 1492, se impuso con las armas, con la violencia, con el dogmatismo, con la eliminación del "otro", sobre el resto de regiones, culturas, pueblos, formas de pensamiento, de creencias, que integran un todo, vivo, llamado el planeta Tierra, para los occidentales, Pacha Mama, para los andino-amazónicos, nuestra Madre Tierra, para todos los pueblos originarios.
\end{abstract}

Palabras clave: Descolonización. Liberación. Pensamiento Latinoamericano. Gestión Cultural.

\section{DAS ARMAS E DAS LETRAS ATÉ PACHAMÃE}

Resumo: Este texto pretende apresentar um longo processo de investigação e ação, com alguns resultados que por sua vez se tornam novas questões, em desdobramentos que abrem outros caminhos e nos conectam por sua vez com outras fontes, com outras investigações, com outras redes que dão corpo e espírito a esta busca árdua e sem fim pelo conhecimento e pela transformação social. No nosso caso, conhecimento(s) e ações que nos levam à descolonização, à libertação, para nos ajudar a superar a opressão e o domínio de uma única forma de pensamento, de um projeto fracassado que nos conduziu à catástrofe civilizacional que estamos vivendo. Projeto colonizador que não acaba e que desde o seu início, em 1492, foi imposto com armas, com violência, com dogmatismo, com a eliminação do "outro", sobre o resto de regiões, culturas, povos, formas de pensamento, de crenças, que integram um todo, vivo, chamado planeta Terra, para os ocidentais, Pacha Mama, para os andinoamazônicos, nossa Mãe Terra, para todos os povos nativos.

Palavras-Chave: Descolonização. Libertação. Pensamento Latino-Americano. Gestão Cultural.

${ }^{1}$ Colombiano, professor do ILUFBA, pesquisador de pós-doutorado na UNAM (México). Idealizador do Coletivo Pachamãe-Integração Latinoamericana. E-mail: casieldante@gmail.com. 
Estas reflexiones fueron la leña que atizó el fuego que daría origen al Colectivo y al Proyecto de Integración Latinoamericana - Pachamãe, del cual trataremos en la segunda parte. Pachamãe surge entonces del deseo de materializar, de concretizar las ideas y teorías levantadas en Las armas y las letras. Por eso, nos parece importante narrar, aunque sea de manera muy amplia, esta experiencia de acción colectiva, con los desafíos, alegrías y sinsabores que ello implica. Pachamãe es un proyecto de extensión universitaria y de investigación vinculado al Departamento de Letras Románicas de la Universidad Federal de Bahía - UFBA, que busca promover la integración latinoamericana, invertir en las letras, en el arte, la cultura, la educación alternativa, para construir caminos de liberación, que apunten a salir del actual estado de armas, de violencia y de la catástrofe civilizatoria a la que nos ha conducido el proyecto fracasado de la Modernidad.

\section{De las armas y las letras}

En diciembre de 2015, en la Universidad Federal de Bahía (Brasil)UFBA, fue defendida la tesis de doctorado: "De las armas y de las letras: la violencia en la Novela Latinoamericana Contemporánea (NLC)". Esta investigación era la continuación de otra anterior, la de la Maestría, cursada en esta misma universidad. Dicho estudio buscó colocar en diálogo a Brasil con los otros países de América Latina, a través de la problematización del llamado "boom de la literatura latinoamericana", que no incluyó a Brasil, al Caribe anglófono y francófono, entre otras exclusiones, así como realizar análisis y reflexiones sobre del proceso de renovación de la narrativa latinoamericana. Éste inicia con las vanguardias en la década del 20 y llega a su punto más alto con el boom en los años 60 del siglo pasado. En esta disertación nos centramos en el estudio particular de la narrativa de Jorge Amado, con el auxilio de los conceptos de "hibridismo cultural" de Canclini (2006) y "transculturación narrativa" de Ángel Rama (1982), para buscar la relación entre la propuesta narrativa del escritor bahiano y la llamada "Nueva Narrativa Latinoamericana", de la cual él como otros escritores de su época, hicieron parte fundamental. 
La lectura de las narrativas literarias e históricas, nos fueron mostrando que lo que sobrevino en América Latina después de este corto periodo de utopía, fue violencia. Violencia de diferentes tipos, de diferentes sectores, en diferentes lugares. De esta manera, nos propusimos estudiar algunas formas de esa violencia en las últimas décadas (80 en adelante), en un corpus amplio y representativo de novelas contemporáneas que abordan estas temáticas de la realidad social en América Latina.

La investigación se dividió en una introducción, cuatro capítulos y consideraciones finales. En la Introducción, denominada: "Novela y sociedad", se hace una pequeña relación entre el origen y evolución de la novela moderna y su contexto social: la historia, la cultura, los fenómenos sociales, políticos, estéticos. Intentamos mostrar cómo la novela moderna surge de ese nuevo orden social que se comienza a desarrollar en los siglos XVI - XVII, con el proceso de Conquista, colonización, afirmación de la burguesía, el capitalismo, los ideales de "desarrollo", "progreso", en fin, el proyecto de Modernidad impuesto por una Europa que por primera vez se entendía a sí misma como centro del mundo, como trae Dussel (1992).

La narrativa, o mejor dicho narrativas, que surgen de esa nueva configuración social son quien mejor cuestionan, critican y problematizan los vicios y consecuencias de ese sistema de injusticia, de destrucción, de egoísmo, competencia y eliminación del "otro". Estas narrativas, en el sentido benjaminiano, contienen la sabiduría de un pueblo, cuentan las historias de los hombres y mujeres comunes y corrientes, los mitos de esta sociedad y por lo tanto, estas narrativas reflejan su verdadero rostro, como el retrato de Doryan Grey. Por eso hablamos del valor epistemológico y ontológico que tiene la novela, la narrativa en general. El viejo arte de contar historias, de transmitir una sabiduría, que nos habla Benjamin (1992), y que según él, constituyen los rasgos esenciales del verdadero Narrador.

En el primer capítulo, denominado: “¿Y después del boom?”, hicimos un recorrido historiográfico de la novela latinoamericana en las últimas décadas. Por un lado, lo primero que identificamos fue la continuidad de algunas de las propuestas estéticas del boom, sus ecos en la siguiente generación de escritores, particularmente del famoso "realismo mágico" que tuvo tanto éxito comercial y por eso se continuó reproduciendo durante años. 
En ese panorama mencionamos a los "novísimos", a la llamada "nueva novela histórica' y a la "novela o narrativa de testimonio", que a lo largo de los años setenta y ochenta ganaron bastante fuerza en el panorama literario de América Latina. Ese auge del "testimonio" se debió, particularmente, a la violencia (desapariciones, torturas, secuestros, represión, etc.) que las dictaduras militares desataron en la sociedad latinoamericana y la necesidad, por parte de muchos escritores, de revisar la historia, de retratar el horror para intentar entender mejor la realidad, dónde se falló.

Por otro lado, en este capítulo también se constató el carácter exclusivista del boom, el cual contempló sólo a algunos escritores (hombres todos, para comenzar), con una estética e ideología particulares. Entre las muchas y muchos excluidos de ese panteón resaltamos el caso de Rubem Fonseca, un autor brasileño que desde los años sesenta mostraba una narrativa ágil, con un lenguaje directo, sucio, violento, con personajes marginales, con tramas truculentas, "un realismo brutal", como lo definió Antonio Cándido (1989) y Alfredo Bosi (2006). Por eso lo ubicamos como un antecesor y un gran maestro del género policial en América Latina, del hiperrealismo y de la estética de la violencia, que actualmente llaman tanto la atención en el panorama narrativo no sólo a nivel local sino global.

El segundo capítulo lo titulamos: "La hora del terror: la Novela Latinoamericana Contemporánea (NLC) y los conflictos político-militares en América Latina". Aquí nos centramos por un lado en la violencia devenida de las dictaduras militares, y por el otro en la violencia desatada por los conflictos guerrilleros. Para el primer caso, nos enfocamos en Chile y Argentina, dos lugares emblemáticos de la violencia y el horror que provocó la Operación Cóndor en Latinoamérica, sin desconocer el sufrimiento de los otros países que pasaron por esta pesadilla. Donde quiera que se imponga el fascismo y el autoritarismo militar, el terror y lo peor del alma humana salen como una jauría de lobos hambrientos. Por razones metodológicas seleccionamos dos novelas que consideramos representativas de esa nueva forma de abordar y narrar la violencia de las dictaduras militares, la cual no toma como eje a la figura del dictador, sino las marcas que esa violencia dejó en las víctimas, en la población civil, en los mismos escritores. Las novelas 
analizadas fueron: Nocturno de Chile (2000), de Roberto Bolaño y Una misma noche (2012), del argentino Leopoldo Brizuela.

Para el análisis de la violencia desatada por los conflictos guerrilleros en América Latina, nos centramos en tres lugares representativos de este fenómeno de nuestra historia reciente y en algunas novelas contemporáneas que lo abordan: Colombia, con Los ejércitos (2006) de Evelio Rosero; Centroamérica, con La sirvienta y el luchador (2011), y El arma en el hombre (2013) de Horacio Castellanos Moya; y Perú con Abril rojo (2006) de Santiago Roncagliolo. Al sumergirnos en estas narraciones, en las historias de vida de esos personajes reales, ficticios o autoficcionales y sus respectivos contextos, nos deparamos con el horror y el sinsentido de la guerra. Guerra(s) por diferencias ideológicas, por intereses privados, por el poder al fin de cuentas, pero guerras en las cuales quien pone los muertos son los más pobres, donde es la población civil quien queda en el medio de la lucha de esos ejércitos y siempre lleva la peor parte.

El capítulo tres se titula: "Llegaron los narcos". En este escenario de violencia de las dictaduras militares, de los conflictos guerrilleros, aparece un nuevo actor, un nuevo personaje: el Narco. Esa es la novedad en esa nueva espiral de violencia. De en medio de ese fuego cruzado por el poder, de esa inmensa población explotada y llena de necesidades básicas, sumadas a todas las otras que impone la exacerbación del deseo del sistema capitalista y neoliberal que ya se ponía en marcha por esos años, surge un nuevo personaje, con su propio lenguaje, su propia moda, sus gustos estrambóticos, que son un simulacro de la estética del nuevo rico norteamericano, como Héctor Abad Faciolince (2015) lo identificó. El Narco entiende que Estado y guerrilla, derecha e izquierda, libran una lucha por el poder, pero en esa realidad, en ese sistema-mundo (capitalista), el poderoso es quien tiene el capital.

El Narco encuentra en el negocio de las drogas la forma de acceder a este hedonismo superficial. Por eso estamos de acuerdo con Carlos Monsiváis cuando afirma que: "La emergencia del narco no es ni la causa ni la consecuencia de la pérdida de valores; es, hasta hoy, el episodio más grave de la criminalidad neoliberal. Si allí está el gran negocio, las víctimas vienen por añadidura. Y con ellas la protección de las mafias del poder" (2004, p. 44). 
A esta espiral del infierno es que nos conduce Fernando Vallejo y Élmer Mendoza con La Virgen de los sicarios (1989) y Balas de plata (2007), novelas que seleccionamos para este análisis. Colombia y México, dos lugares arquetípicos del narcotráfico, de la lucha contra las drogas, de la narcocultura. En el caso de la novela de Vallejo, que consideramos no solo una de las grandes novelas de las últimas décadas sino de todo el siglo XX en América Latina, a través de una autoficción, se produce un descenso al Hades, que es la Medellín de lo años 80, en pleno auge del narcotráfico, de la lucha entre carteles, de la disputa entre los narcos y el Estado. Siguiendo uno de los grandes tópicos de la literatura universal, el del héroe que tras años de exilio vuelve a casa, Vallejo nos pasea y nos presenta (con su humor negro y muy inteligente, que pocos entienden, con su ironía, rabia, desencanto y profunda crítica) su mirada del infierno, del apocalipsis que sobrevino sobre su ciudad natal, tomada por el crimen, la violencia, la ética y los códigos (hasta lingüísticos) propios de la narcocultura, acompañado por sus jóvenes Virgílios, los sicarios (Alexis y Wilmar, la Laguna Azul), amantes, guías, victimarios y víctimas a la vez de ese horror.

La Virgen de los sicarios es una obra pionera de la llamada narcoliteratura, en el sentido de mostrar desde dentro este universo, con su particular lenguaje, "El parlache", del cual el narrador al inicio se espanta, por lo que hicieron con la lengua esos jóvenes sicarios, pero después se apropia, lo incorpora, juega y se divierte con él. Es también una obra representativa de la autoficción, del hiperrealismo, de la estética de la violencia, del genero de la diatriba. Es una radiografía cruda, pero profundamente, honesta y sincera, como lo es su autor, de Colombia y de su realidad. La Virgen de los sicarios es todo esto y mucho más, como toda gran obra maestra.

Balas de plata, la novela de Elmer Mendoza, es una obra mucho más sencilla, a nivel estilístico, del lenguaje (aunque es de resaltar su novedoso y audaz uso de la lengua popular de Sinaloa, del llamado “culichi”), de la profundidad, entre otros aspectos, pero significativa de la violencia que se vive en las primeras décadas de este siglo en México. Esa oleada de violencia surge debido a la guerra contra las drogas desatada en Colombia, pero incentivada y subsidiada por Estados Unidos, que produjo lo que algunos sociólogos llaman "Efecto balón". Es decir, al reprimir en Colombia, se 
expande en México, país desde siempre productor y comercializador de drogas, pero, sobre todo, vecino del mayor consumidor de estupefacientes: Estados Unidos.

A través de un roman noir, de un thriller policial, y del desarrollo de su intriga: la investigación del crimen de Bruno Canizales, el narrador y las diferentes voces que conforman el relato, van presentando la corrupción que inunda al Estado y sus instituciones, así como el poder del narcotráfico en las cuestiones políticas, económicas y culturales de la sociedad mexicana.

Mendoza y Vallejo, con sus estilos particulares, están mostrando que el problema de la violencia que viven las sociedades dominadas por el narcotráfico no es sólo responsabilidad del narco, del sicario, del delincuente, sino también de la policía, de los políticos, de los gobernantes (incluidos los presidentes), en definitiva, del Estado. Esta es la doble moral burguesa, que es también la doble moral cristiana y es la moral que domina nuestra sociedad moderna, eurocéntrica, patriarcal, blanca, capitalista y neoliberal.

El cuarto capítulo, llamado "Continúan ganando las Armas: la Novela Latinoamericana Contemporánea (NLC) y el crimen globalizado”, se centra en lo que denominamos "la violencia de la globalización". Las novelas seleccionadas para análisis fueron: Trilogía sucia de la Habana (1998), del cubano Pedro Juan Gutiérrez, y Cidade de Deus (1997), del brasileño Paulo Lins. En la primera parte del capítulo hacemos un análisis del concepto de "globalización", a partir principalmente de los estudios de Milton Santos (2000), el cual define tres tipos de globalización: la globalización como fábula, que es la que nos vende el sistema y los medios de comunicación; la globalización como es: perversa; y la globalización como debería ser, es decir, una globalización más humana.

La globalización "perversa", que es la real, la que vivimos, se impone a través de lo que el pensador brasileño llama, la "tiranía del dinero" y "la tiranía de la información", creando la fábula de una falsa integración, de una falsa igualdad y homogeneización, cuando en realidad la exclusión, la desigualdad y el totalitarismo de la pobreza es lo que caracteriza a la globalización que vivimos. Como Milton Santos afirma, siempre existió la pobreza, pero nunca antes ella fue parte estructural del sistema, necesaria para que una pequeña minoría sea privilegiada y continúe acumulando y 
reproduciendo el capital mundial, en cuanto la inmensa mayoría es explotada, segregada y manipulada por el miedo líquido que habla Bauman (2006), por el odio al "otro" y la violencia que la amalgama de estos factores desencadena.

En seguida, los análisis se centran en dos lugares aparentemente antagónicos dentro del modelo de globalización. Por un lado, Cuba, un país que desde el triunfo de la Revolución en 1959 entra en un modelo de socialismo, con la idea del "nuevo hombre", de una sociedad más justa e igualitaria, en directa contravía a la globalización capitalista. Por el otro lado, Brasil, un país que entra de cara en el proyecto de modernidad, de "orden y progreso", de desarrollo, que propone ilusoriamente la globalización capitalista.

Con Pedro Juan Gutiérrez y su Trilogía sucia..., nos sumergimos en una narración autoficcional, dura y cruda, donde el autor nos presenta, a través de los diferentes relatos que conforman la novela, la realidad que tiene que vivir en su barrio natal Centro Habana, para sobrevivir en el llamado "Periodo Especial". Durante este periodo, que inicia en los años noventa, tras la caída del Muro de Berlín y la disolución de Unión Soviética, Cuba vivió una de sus peores crisis económicas, debido principalmente a la pérdida de apoyo financiero por parte del bloque comunista y al severo bloqueo económico que le impone Estados Unidos.

Cidade de Deus de Paulo Lins, es una novela que tiene estrecha relación con la Trilogía de Pedro Juan Gutiérrez. Así como este último, Paulo Lins también construye una especie de trilogía (la novela está dividida en tres partes), por eso, jugando con los nombres, titulamos esa parte del análisis como "La trilogía sucia de Paulo Lins", en la cual el autor utiliza también sus experiencias de vida en la favela carioca Cidade de Deus, como material narrativo para mostrar la historia de violencia sufrida por esta localidad a lo largo de tres generaciones: "La historia de Inferninho", "La historia de Pardalzinho" y “La historia de Zé Miúdo".

Desde los años 60 hasta los 80, marco histórico en el que se inscribe la novela, que corresponde al periodo de dictadura militar y entrada a la democracia en Brasil, Lins nos va mostrando cómo en esa historia de Cidade de Deus, que es una metáfora de Brasil, las violencias atávicas (como la relación entre señores y esclavos, es decir entre blancos y negros), se mezclan 
con la violencia militar, el narcotráfico, la delincuencia y demás formas de violencias subjetivas que produce la violencia sistémica, la pobreza estructural y la enorme desigualdad social.

En este sentido, Lins presenta, de manera desnuda y cruda, el Brasil que nadie quiere ver, con su rostro desfigurado, grotesco y perverso; nos muestra la pobreza, la violencia, la corrupción, la impunidad que caracteriza su historia reciente, desde el golpe militar en el 64 hasta el inicio de la guerra contra las drogas y la delincuencia en los años 80 y, cómo en esa historia, Brasil entró en el modelo de globalización perversa que desemboca en la actual crisis que vive el país.

Así, en el contrapunto entre la Trilogía de Gutiérrez y la de Lins, que a su vez es el contrapunto entre Cuba y Brasil, un país que no entra en el modelo de globalización y otro que sí, se puede ver que por fuerte y problemática que sea la realidad cubana que presenta el primero, la visión de Lins sobre Brasil es mucho más desalentadora y preocupante. En la novela de Gutiérrez se retrata la violencia que produce la pobreza que impone y propicia la tiranía del dinero, la globalización capitalista, como apuntamos, pero también se logra vislumbrar la sobrevivencia y resistencia del pueblo a través del rebusque, de la fiesta, del humor, la sensualidad caribeña, pero sobre todo a través de las redes de solidaridad y apoyo que construyen los cubanos, las cuales les permite seguir adelante.

Ya en Cidade de Deus, como en La virgen de los sicarios de Vallejo (en Colombia, otro país que entra de lleno en el modelo de globalización y neoliberalismo), vemos que los actores y las víctimas de la guerra, principalmente son jóvenes y niños. Son ellos, de un lado o del otro, que empuñan las armas y libran una guerra fratricida que parece nunca acabar, sino que se reproduce y empeora de generación en generación. "A favela é nossa" (la favela es nuestra), gritan los niños empuñando las armas en la última escena de la adaptación al cine de la novela de Lins por parte de Fernando Meirelles (2003).

Este retrato espeluznante es el reflejo de un país que nunca superó la esclavitud, el racismo, el machismo, el militarismo, sino que recicló estas violencias y las incorporó o subsumió, como diría Enrique Dussel, en el modelo de globalización perversa, agregando a este coctel letal, la violencia y 
la barbarie que producen "la tiranía del dinero" y la "tiranía de la información", propias del modelo de globalización hegemónico.

Lo anterior se puede ver claramente en el actual panorama económico, político y social de Brasil, donde gracias a la alianza entre los medios de comunicación (la red Globo, particularmente), la corrupta clase política y los sectores económicos dominantes, logran ejecutar un golpe político a la primera mujer en llegar a la presidencia del Brasil y a ser reelegida democráticamente para su segundo mandato. Logran encarcelar, juzgar y condenar, sin pruebas, a uno de los mayores líderes populares de América Latina, como lo es Ignacio Lula da Silva; y lo peor de todo, logran dividir a la población y generar el odio entre ellos por diferencias partidarias (el lastre de toda América Latina), reviviendo monstruos del pasado que se creían extintos o superados, pero que en realidad siempre han permanecido latentes y al acecho: el racismo, el machismo, la homofobia, la xenofobia, el fascismo... Monstruos que buscan imponerse y dominar a cualquier costo, aunque esto implique la destrucción de las garantías sociales, de los "derechos humanos", de los recursos naturales, de la propia vida, como lo está demostrando el actual gobierno Bolsonaro.

De esta manera y respondiendo a la pregunta que se formuló al inicio de la investigación: ¿cuál es la verdad, el mensaje que nos revela estas narrativas sobre la sociedad latinoamericana contemporánea? Podemos observar que todas ellas (y podríamos agregar muchas más), aunque sean escritas por diferentes autores, en diferentes lugares, con diferentes estilos, parecen conformar lo que llamamos "una ópera macabra del horror" que sobrevino en América Latina. En diversos actos, con variados escenarios, todas ellas presentan el estado de guerra, de destrucción del tejido social, del miedo y del odio que impone el actual sistema de dominación y el desastre al que nos condujo su fracasado proyecto de Modernidad y sus consignas de "desarrollo" y "progreso".

Una de las reflexiones que permitió Las armas y las letras es que para salir de este estado de Armas, de violencia, es necesario invertir en las Letras, entendiendo esta idea como la construcción de una globalización más humana, más justa, más equilibrada. Vivimos en una crisis no sólo económica, social, sino una crisis política, humana y ambiental de magnitud mundial. 
Tornamos el mundo una Sodoma y Gomorra, como vimos en este estudio y los recientes acontecimientos mundiales lo comprueban: millares de personas muriendo en el Mediterráneo expulsadas por la guerra en sus países; estudiantes y líderes sociales, indígenas, asesinados y desaparecidos por la policía y ejércitos para(militares) en diferentes lugares de América Latina; guerras y conflictos político-militares en Israel, en Palestina, en Siria, en Nigeria, en Colombia, en Venezuela, en Perú, en Brasil... Se están quemando selvas y reservas forestales a lo largo del planeta, incendios muchas veces propiciados por los terratenientes locales, por los ganaderos ambiciosos e inescrupulosos; están muriendo ríos; el plástico y la basura que producimos inundan los mares y hacen cada vez más inviable el hábitat de las especies marinas. Y para rematar: Pandemia (o Plan-demia, como está siendo denominada por algunos sectores críticos), cuarentena global, algo nunca antes visto en toda la historia de la humanidad. Todo un proyecto de exterminio masivo, a nivel planetario. Una profilaxis de personas, de los más viejos, de los más débiles, de los más pobres, que para el sistema representan apenas gastos innecesarios. Pero son seres humanos, son nuestros abuelos que están muriendo y con ellos su memoria, su historia, su sabiduría. Estamos viviendo un momento histórico sin precedentes, estamos siendo testigos de la catástrofe civilizatoria a la que nos arrastró la Modernidad como sistema de pensamiento, como horizonte epistemológico, el ego-cogito cartesiano, que es el "yo conquisto" como lo trae muy bien Enrique Dussel en diferentes textos, pero particularmente en 1492. El encubrimiento del otro. El origen del mito de la Modernidad (1992). Ese "yo conquisto" que se impone con la espada y la cruz y que produce el individualismo aniquilador que niega al "otro", que se cierra ante el grito del pobre, del hambriento, de la anciana, de la mujer, del inmigrante, de su "prójimo".

Para terminar esta parte, nos parece importante decir que Las armas y las letras nos llevó a pensar y a entender el papel fundamental de la educación para la transformación social. Pero no la educación tradicional, oficial, que se viene impartiendo en la mayoría de escuelas y universidades, la cual está al servicio del sistema, de la reproducción de sus estructuras y fundamentos, de la capacitación de mano de obra para su proyecto de producción y dominación, de acumulación desmedida de capital y de muerte, 
como lo estamos viviendo. Por eso debe ser una educación redentora, liberadora, transgresora, subversiva, si se quiere. Una educación, en todo caso, que rompa con las viejas estructuras, que permita la reflexión crítica, la descolonización de nuestro pensamiento, la conciencia del individuo consigo mismo, con su entorno, y lo lleve a hacer parte activa en la construcción de un mundo más justo y equilibrado para él y las demás formas de vida que lo rodean:

La reflexión final que trae este estudio es que, a través de las letras, de esa educación liberadora, del proceso de sacar las máscaras y vernos como somos, aceptarnos como somos y amarnos como somos, posiblemente podremos construir esa globalización humanista de amor y de vida, y así intentar rescatar nuestra especie del abismo al que parece estar condenada por los señores de las armas (VELASQUEZ, 2015, p. 441).

\section{Pachamãe - Integración Latinoamericana}

Con estas reflexiones alcanzadas en Las armas y las letras se cerraba una espiral para dar inicio a otra. La pregunta que surgía en ese nuevo momento era: ¿cómo hacer posible esto? ¿Cómo pasar de la teoría a la práctica? Eso por un lado, por el otro estaba el hecho de haber estado sumergidos durante cinco años en el tema de la violencia, histórica, atávica, y también la del presente, del ahora, y cómo todo ese proceso nos había afectado como sujetos. La inmersión en esos mundos narrativos de la violencia reciente en América Latina, nos reveló la necesidad de apostar en el amor y en la vida para salir del camino del odio y de la muerte que ha impuesto el sistema-mundo actual. De esa conjunción de elementos, de reflexiones y emociones, surge Pachamãe, como una alternativa frente al panorama de muerte y el horror que vimos en Las armas y las letras, y la forma de materializar, de colocar en práctica las ideas y reflexiones alcanzadas en este estudio.

El mito dice que en una fiesta unos amigos se encuentran después de algunos años y de muchos viajes y comienzan a hablar sobre la crisis social, humana, planetaria, de la situación de Colombia, Brasil, Argentina, de Bahía, 
mientras beben, ríen y bailan al ritmo de Calle 13, Bomba Estéreo, Systemasolar, Crioulo, Tim Maia, Jorge Benjor, Seu Jorge, BaianaSystem... Y mientras intercalan otras historias muy diferentes a ese "papo cabeça”, un@ de ell@s le dice al otr@ que la humanidad no puede continuar por la vía de las armas, de la violencia, del egoísmo, del individualismo, que es necesario invertir en las letras, en una educación liberadora, en el arte, en la cultura, para poder equilibrar mejor la cosa. Les propone a sus amig@s una parcería (en el sentido brasileño y colombiano), para hacer un proyecto de integración latinoamericana en Salvador, donde ell@s están, pero que se amplíe en otros lugares donde haya otras personas, parceir@S, que entiendan también esa necesidad de construcción. Un@ de ell@s responde que ya no es más el productor cultural del proyecto donde hacía parte, que salió porque el coordinador tenía una idea más cerrada, más personal, y entonces decidió alejarse. Otr@ dice que junt@s pueden hacer lo que quieran, lo que siempre soñaron. Luego brindan, se abrazan, beben, gritan !que viva Latinoamérica!, !la amistad!, !la vida!, y se entregan a la fiesta...

Est@s amig@s juntan otr@s amig@s, se ayudan de las redes sociales y las nuevas tecnologías para poderse conectar y compartir ideas, proyectos, para soñar en colectivo; surge entonces la necesidad de tener un nombre, una idea que los conecte y represente. Aparecen varias propuestas hasta que en común acuerdo se decide por Pachamãe, ya que remite al concepto de Pachamama de los pueblos andinos, que significa: Tierra-Madre, literalmente. Sin embargo, su significado más profundo nos remite a la idea de ver la naturaleza no como objeto, de extracción, explotación, estudio o lo que sea, sino como lo que es, la fuente creadora de todas las formas de vida que habitan el planeta Tierra, nuestra madre, nuestra PachaMama. Nos conectaba, de esta manera, el pensamiento colectivo sobre la necesidad de recuperar la conexión con la tierra, con las otras formas de vida, no apenas la humana, de fortalecer nuestras raíces, nuestra ancestralidad, nuestra relación con la Madre Tierra.

Jugando con el portuñol, ya que varios de los integrantes del grupo somos extranjer@s en Brasil, decidimos llamarnos: Pachamãe. Pero había otra idea, otro concepto común que nos identificaba y no queríamos dejar por fuera: la Integración Latinoamericana. Tod@s a través de nuestras 
experiencias personales de inmigrantes, extranjer@s, habíamos observado y confirmado la falta de conocimiento y de diálogo que hay entre Brasil y los otros países de América Latina. Como dijimos al inicio de este texto, este tema constituye un proyecto de vida e inclusive fue el que nos llevó a Brasil a realizar la Maestría en la UFBA.

Además, todos los integrantes del colectivo sentíamos la nostalgia, mejor sería decir, la saudade, como se dice en Brasil, de nuestra música, de nuestras fiestas, de nuestras comidas, por eso nos reuníamos espontáneamente a "matar essas saudades", haciendo nuestros "encuentros latinos", y los brasileños que asistían quedaban encantados. Era una forma de conectarnos con nuestra tierra, con nuestras raíces y a la vez darle a conocer a nuestras amigas y amigos, hermanas y hermanos brasileños, estas manifestaciones culturales. Nos unía por lo tanto el deseo de dar a conocer, de compartir, la cultura de los diferentes países de América Latina en Brasil, en diálogo con su cultura, con su historia, con sus raíces africanas, por ejemplo. Nos parecía importante además, fortalecer el concepto y el sentimiento de "ser latinoamericano", del amor a la "Patria grande", que es tan débil en Brasil, pues históricamente (como el resto de América Latina) ha fijado su mirada, su modelo de cultura, en el Norte: Europa y Estados Unidos, quedando de espaldas a sus vecinos.

De esta manera, en agosto de 2016, en el barrio de Santo Antônio Além do Carmo, en la ciudad de Salvador de Bahía de Todos los Santos, surge el Colectivo: Pachamãe - Integración Latinoamericana. El lanzamiento del proyecto se realizó en un espacio cultural llamado RangoVegan, el cual trabaja con la consigna de alimentación vegana, de activismo alimentario. La programación incluyó danza, poesía, música en vivo, comida, bebida y mucha alegría. Al final leímos nuestro Manifiesto Pachamãe. Era nuestra primera intervención pública, salíamos de la sala de clase, de la Universidad, de los libros, a la calle, al mundo del arte y la cultura alternativas.

El objetivo principal de Pachamãe es, como señalamos antes, invertir en las Letras, en una educación liberadora, en la descolonización del pensamiento, en el arte y la cultura alternativa, para construir caminos que posibiliten salir del estado de Armas, de guerra, violencia y muerte al que la 
Modernidad, el EUrocentrismo, el patriarcado y el capitalismo nos han impuesto y nos tienen en la actual catástrofe civilizatoria.

Bajo esta consigna, comenzamos a hacer intervenciones tanto en la UFBA, como en otros espacios académicos y culturales de Salvador. Desde su origen, nos trazamos tres frentes principales de acción: el campo académico (las clases en la universidad, seminarios, conferencias, charlas, etc.), la extensión universitaria (intervenciones artísticas y culturales, fiestas, conversatorios, talleres y demás formas de encuentro fuera de la universidad, en la comunidad) y el ambiente virtual (internet, redes sociales, blogs, etc.). En esta perspectiva, a lo largo de estos cuatro años de existencia del proyecto Pachamãe, en las disciplinas que hemos impartido en la Universidad (en el Departamento de Letras Románicas de la UFBA), así como en los diferentes cursos, seminarios, talleres, congresos, simposios y demás actividades académicas en las que hemos participado, hemos procurado promover y colocar en práctica los objetivos antes mencionados. Igualmente ha sucedido con el campo de la investigación, los proyectos que venimos desarrollando están directamente relacionados con los principios Pachamãe, como se puede ver a lo largo del presente texto.

El Colectivo desde el 2016 está registrado como "Proyecto permanente de extensión universitaria" en la UFBA y está registrado como Punto de Cultura en la ciudad de Salvador. Vale la pena destacar que principalmente al inicio nos centramos en la producción de eventos de carácter presencial, nos interesaba la acción y la intervención colectiva en la comunidad, en espacios culturales, pero también públicos, con presencia real. En ese momento nos movía más la acción, la extensión, salir de los muros (en el amplio sentido del termino) de la academia, de la "uni" - versidad, nos interesaba justamente lo "pluri", lo diverso, lo diferente, lo que no entra en los moldes eurocéntricos, elitistas y exclusivistas del academicismo tradicional, que dominan hasta nuestros días los modelos, programas y ejercicio concreto de la educación oficial de nuestra sociedad Moderna.

Con relación al campo virtual, desde el inicio del Colectivo intuimos la necesidad y la importancia del espacio virtual, de Internet y las nuevas tecnologías para poner en práctica nuestros propósitos. Así, desde el 2016 creamos nuestra página en Facebook (facebook.com/pachamae), Instagram 
(@pachamae),

Youtube

(https://www.youtube.com/channel/UCfxmkb6oNjeAKAwV34XWShw/);

creamos también un blog (https://pachamaeblog.wordpress.com/), todo con la intención de darle difusión y promoción a las actividades organizadas por el Colectivo, así como para compartir informaciones, ideas, contenidos y demás acciones que organizamos.

Inicialmente el espacio virtual era un soporte y alternativa al trabajo desarrollado por el Colectivo, pues como señalamos antes, la prioridad eran los eventos presenciales, mucho más después de conseguir tener una sede: La Casa Pachamãe. Sin embargo, con el inicio de la Pandemia mundial a causa del Covid-19 y de la cuarentena obligatoria desde marzo de 2020, la plataforma virtual ha pasado a ser nuestro campo principal de encuentro y de acción del Colectivo. Pero antes hablemos un poco de la Casa Pachamãe.

Como ya dijimos, desde el 2016 comenzamos a organizar eventos y diferentes tipos de encuentros en espacios culturales en la Ciudad de Salvador, así como en la UFBA y otras instituciones académicas ${ }^{2}$, pero desde 2017 conseguimos una sede fija, que era un objetivo importante para nosotr@s desde que nació el proyecto: La Casa Pachamãe. La Casa se ubica en el barrio Monteserrat, en la Avenida Constelação de la llamada Cidade Baixa, en Salvador de Bahía. Se trata de un área periférica de la ciudad, con poca oferta de espacios culturales y de aprendizaje para la comunidad: en su mayoría afrodescendiente, de pescadores, que vive en condiciones humildes, pero logra convivir en paz y armonía. Esta comunidad además cuenta con un número importante de niños, adolescentes y jóvenes. La Casa Pachamãe abrió sus puertas a este y otros públicos que deseaban encontrar un espacio para dejar fluir el arte, su lado lúdico, para aprender más sobre la historia y la riqueza cultural de los pueblos que conforman América Latina; para acoger a tod@s l@s que creen en las letras, en la educación, en la vida y no en las armas, la violencia, la muerte.

Entrar en la comunidad, lograr la aceptación, especialmente cuando varios de los miembros de Pachamãe somos extranjer@s (gring@s, en la jerga

\footnotetext{
${ }^{2}$ Anexamos nuestro Portfolio donde están registradas las principales actividades que hemos organizado como Colectivo.
} 
popular), no fue una tarea fácil. Fue un proceso lento de construcción, con mucho tacto, paciencia y resistencia. Afortunadamente, este trabajo fue recompensado con el sentido de apropiación del espacio que la comunidad mostró, participando en los diferentes eventos organizados allí: talleres con estudiantes y maestros del Departamento de Letras Románicas de la Ufba, talleres de baile, percusión, fotografía, veladas, bazares, cine con adultos y niños, fiestas latinoamericanas, y demás tipos de encuentros artísticos, culturales, donde pudimos vivenciar una verdadera integración latinoamericana en tierras brasileñas, bahianas.

Queríamos que la Casa Pachamãe se convirtiera en una referencia en la ciudad de Salvador, como punto de encuentro y difusión de la diversidad cultural de América Latina. Igualmente, la Casa se abrió a otros proyectos e iniciativas artísticas y culturales, creando asociaciones y redes de apoyo. Esto se materializó con la visita y participación de diferentes amig@s, investigadores, artistas de Brasil y otros lugares de América Latina y el mundo. Tod@s ell@s han compartido su arte y conocimiento en la Casa Pachamãe y en algunos eventos organizados en ambientes académicos. Es importante destacar las asociaciones que se han hecho con maestros y grupos universitarios, y más recientemente, con la creación del colectivo CASAS (Casas Alternativas de Salvador), del cual Pachamãe hasta hoy hace parte. Este colectivo fue fundado con la intención de fortalecer los espacios alternativos de Salvador a través de la unión, la cooperación mutua, el trabajo colectivo.

Para finalizar esta rápida descripción de la Casa Pachamãe, nos gustaría decir que éste ha sido un excelente laboratorio para colocar en práctica muchas de las ideas y conceptos levantados en el campo teórico, en la investigación académica, con todas las dificultades que se presentan, más cuando no hemos contado con ninguna ayuda económica por parte de ninguna institución u organización. Hasta ahora hemos sido totalmente autosustentables.

La Casa Pachamáe surgió de la necesidad de apostar en el amor, en el cuidado, en el acogimiento, para no sucumbir a esa avalancha de odio, guerra y destrucción que los señores de las armas y el capital han provocado. Fueron 3 años de trabajo, de actividades, de entrega y de desafíos que implica 
el trabajo colectivo, el hacer comunidad, por pequeña que ésta sea. Muchas personas pasaron por la casa, conseguimos visualizar la Comunidade da Constelação, aprender con ellos, compartir un poco de nuestras culturas, de nuestros orígenes y conocer más los de ellas y ellos. Con otros horizontes de pensamiento, sin ningún interés económico o político (en el sentido partidista, panfletario, interesado, manipulador), logramos llevar otras prácticas, hacer otras construcciones, aproximarnos a la realidad de esta localidad y vivirla junto con ellos, pensando en transformarla y con pequeñas acciones llevarlo a la práctica.

En 2020 con la Pandemia y el viaje del coordinador del Colectivo Pachamãe a México para realizar una estancia postdoctoral bajo la orientación del pensador latinoamericano, fundador de la Filosofía de la Liberación, Enrique Dussel y el pensador boliviano Juan José Bautista, la Casa Pachamãe cierra temporalmente sus puertas. Este año ha sido importante para dar una pausa y dedicarnos al estudio y consolidación de nuestros fundamentos filosóficos, ontológicos, con la ayuda de los maestros antes citados, pensadores latinoamericanos que están abriendo nuevos horizontes para "adiar o fim do mundo", como dice Ailton Krenak (2019).

El espacio virtual que desde el inicio del proyecto lo pensamos como un frente importante de acción, complementario al trabajo presencial en la Casa Pachamãe o en los otros lugares de nuestras actividades, se convirtió con el "aislamiento preventivo" y la cuarentena permanente, en nuestro principal espacio de encuentro. De este modo, nos tuvimos que adaptar rápidamente a la llamada "nueva realidad" y a través de Zoom, WhatsApp, Lives, y otras plataformas y recursos tecnológicos, continuamos organizando eventos virtuales (saraus, conversatorios, seminarios, entrevistas, charlas, fiestas), conectándonos desde México, Brasil, Colombia, Argentina, Perú y otras latitudes. Hemos aprendido a aprovechar estos recursos para compartir ideas, utopías, pero también música, poesía, reflexiones sobre la realidad, para integrarnos como latinoamericanos, como hermanos que creen y luchan por la descolonización del pensamiento, por la liberación de la opresión de ese mundo moderno, patriarcal, eurocéntrico, capitalista, neoliberal, de muerte y no de vida, que continúa dominando, explotando, aniquilando y nos tiene viviendo (y muriendo) estos tiempos pandémicos. 


\section{Referências}

ABAD FACIOLINCE, Héctor. Estética y narcotráfico. Revista de Estudios Hispánicos, v.42, n.3. 2008. Disponible en: < http://dialnet.unirioja.es/servlet/articulo?codigo $=2880432>$. Revisado el: 29 ago. 2015.

BATAILLON, Gilles. Narcotráfico y corrupción: las formas de la violencia en México en el siglo XXI. Nueva Sociedad, n.255, p. 54-68, jan./fev. 2015. Disponible en: < http://nuso. org/articulo/narcotrafico-y-corrupcion-lasformas-de-la-violencia-en-mexico-en-el-siglo-xxi>. Revisado en: 19 set. 2014.

BAUMAN, Zygmunt. Medo líquido. Rio de Janeiro: Zahar, 2008.

BENJAMIN, Walter. "O narrador: considerações sobre a obra de Nicolai Leskov". In: BENJAMIN, Walter. Obras escolhidas. Magia e técnica, arte e poética. São Paulo: Brasiliense, 1996. p. 197-221.

BENJAMIN, Walter. "Tesis sobre el concepto de historia". In: BENJAMIN. Iluminaciones. Barcelona: Ed. Taurus, 2018, p. 307-318.

BOLAÑO, Roberto. Nocturno de Chile. Barcelona: Editora Anagrama, 2000.

BOSI, Alfredo. Historia concisa da literatura brasileira. São Paulo: Cultrix, 2006.

BRIZUELA, Leopoldo. Una misma noche. Barcelona: Editora Alfaguara, 2012.

CALDERÓN, Verónica. Esta no es otra novela más sobre la dictadura argentina [entrevista]. El País, Madrid, 26 mayo 2012. Diponible en: < http://cultura. elpais.com/cultura/ 2012/05/26/actualidad/1338058545_091277.html >. Revisado en: 10 jul. 2015.

CANDIDO, Antonio. A nova narrativa. In: CANDIDO, Antonio. A educação pela noite e outros ensaios. São Paulo: Ática, 1989. p. 199-215.

CASTELLANOS MOYA, Horacio. El arma en el hombre. Barcelona: Editora Tusquets, 2013, primeira edição 2001.

CASTELLANOS MOYA, Horacio. La sirvienta y el luchador. México, D.F.: Editora Tusquets, 2011.

CLARK, Stephen. El rey de Centro Habana: Conversación con Pedro Juan Gutiérrez. 2000. Disponible en: < htpp://www.librusa.com/entrevista7.htm >. Revisado en: 13 nov. 2015. 
DUSSEL, Enrique. 1492. El encubrimiento del otro. El origen del mito de la Modernidad. Buenos Aires, Ed. Docencia: 1992.

GARCÍA, CANCLINI, Néstor. Culturas Híbridas: Estratégias para entrar e sair da modernidade. Traduc , ão de Ana Regina Lessa e Heloísa Pezza Cintrão. São Paulo: EDUSP, 2006. Título original: Culturas Híbridas: Estratégias para Entrar e Salir de la Modernidad.

GUTIERREZ, Trilogía sucia de la Habana. Barcelona, Anagrama, 1998.

KRENAK, Ailton. Ideias para adiar o fim do mundo. São Paulo: Companhia das Letras, 2019.

LINS, Paulo. Cidade de Deus. São Paulo: Companhia das Letras, 2002.

MENDOZA, Élmer. Balas de plata. Barcelona: Editora Tusquets, 2008.

MEZA, Gerardo; ARIZMENDI, Martha. Función social de la literatura en la obra de Élmer Mendoza. In: MENDOZA, Élmer: Visión de una realidad literaria. México D.F.: Universidad Autónoma del Estado de México: Universidad Autónoma de Sinaloa, 2013. p. 85-96.

MONSIVAIS, Carlos. El Narcotráfico y sus legiones. In: MONSIVAIS, Carlos et al. En Viento rojo: diez historias del narco en México. México, D. F.: Ed. Plaza y Janés, 2004.

RAMA, Ángel. Los procesos de transculturación en la narrativa latinoamericana. In: RAMA, Ángel. La novela en América Latina. Panoramas 1920 -1980. Bogotá: Procultura, 1982, p. 203-229.

RODRÍGUEZ FREIRE, Raúl. Entrevista a Horacio Castellano Moya. Hispamerica: Revista de Literatura, College Parkv.40, n.118, p. 57-70, 2011.

RONCANGLIOLO, Santiago. Abril rojo. Madrid: Ed. Santillana, 2006.

ROSERO, Evelio. Los ejércitos. Barcelona: Editora Tusquets, 2006.

SANTOS, Milton. Por uma outra globalização: do pensamento único à consciência universal. Rio de Janeiro: Record, 2000.

VALLEJO, Fernando. La Virgen de los sicarios. Bogotá: Editora Alfaguara, 2003.

VALLEJO, Fernando. La Virgen de los sicarios. Bogotá: Editora Alfaguara, 2003.

VELÁSQUEZ ROMERO, Dani. Jorge Amado e O Novo Romance Latinoamericano: processos de hibridação cultural em Dona Flor e seus dois maridos 
DE LAS ARMAS Y LAS LETRAS HACIA PACHAMẦE

e O sumiço da santa. 2010. 142 f. Dissertação (Mestrado em Letras) Instituto de Letras, Universidade Federal da Bahia, Salvador, 2010.

VELÁSQUEZ ROMERO, Dani. Las armas y las letras. La violencia en la novela latinoamericana contemporánea. $438 \mathrm{f}$. Tesis (Doctorado en Literatura y Cultura) Programa de Pos-graduación en Letras, Universidad Federal da Bahía, Salvador, 2015.

ŽIŽEK, Slavoj. Sobre la violencia: seis reflexiones marginales. Barcelona: Ed. Planeta, 2009.

Recebido em 20 de novembro de 2020

Aceito em 15 de dezembro de 2020 